\title{
Characterization of occupational, demographic and health determinants in Canadian reservists veterans and the relationship with poor self-rated health
}

\author{
Julian Reyes ${ }^{*} \mathbb{D}$, Jill Sweet, MaryBeth MacLean, Alain Poirier and Linda VanTil
}

\begin{abstract}
Background: Self-rated health is an useful indicator of the general health in specific populations and used to propose interventions after service in the military context. However, there is scarce literature about self- rated health (SRH) in the Canadian Veterans of the Reserve Force and its relationship with demographic, health and occupational characteristics of this specific group. The aims of this research were to determine the SRH in Canadian Reserve Force Veterans and to explore the relationship between demographic, military service and health factors by reserve class.
\end{abstract}

Methods: Data from the individuals was collected from the Life After Service (LASS) 2013 survey, including Veterans with Reserve Class C $(n=922)$ and Class A/B $(n=476)$. Bivariate and multivariate analysis using logistic regression models, were used to assess the association between the demographic characteristics, physical health, mental health, and military service characteristics and the self-rate health by both reserve classes.

Results: The overall prevalence of poor SRH in Reserve Class C Veterans was 13.1\% (Cl:11.08-15.4) and for Reserve Class A/B was 6.9\% (Cl:5.0-9.1). Different degrees of associations were observed during the bivariate analysis and two different models were produced for each reserve class. Veterans of Reserve Class $C$ showed that being single was $(\mathrm{OR}=2.76, \mathrm{Cl}: 1.47-5.16)$, being 50-59 years old $(\mathrm{OR}=4.6, \mathrm{Cl}: 1.28-17.11)$, reporting arthritis $(\mathrm{OR}=2.49, \mathrm{Cl}: 1.33-4.67)$, back problems $(\mathrm{OR}=3.02, \mathrm{Cl}: 1.76-5.16)$, being obese $(\mathrm{OR}=1.96$, $\mathrm{Cl}: 1.13-3.38)$, depression $(\mathrm{OR}=2.34, \mathrm{Cl}: 1.28-4.20)$, anxiety (OR=4.11, Cl: 2.00-8.42), PTSD (OR=2.1 Cl: 0.98-4.47), and being medically released (OR=4.48, Cl: 2.43-8.24) were all associated with higher odds of poor SRH. The Reserve Class A/B model showed that completing high school $(\mathrm{OR}=4.30, \mathrm{Cl}: 1.37-13.81)$, reporting arthritis $(\mathrm{OR}=6.60, \mathrm{Cl}: 2.15-20.23)$, diabetes $(\mathrm{OR}=11.19, \mathrm{Cl}: 2.72-46.0)$, being obese $(\mathrm{OR}=3.37, \mathrm{Cl}: 1.37-8.27)$, daily smoking $(\mathrm{OR}=2.98, \mathrm{Cl}: 1.05-8.38)$, having anxiety $(\mathrm{OR}=9.8, \mathrm{Cl}: 3.70-25.75)$ were associated with higher odds of poor SRH.

Conclusions: These results suggested that the relationship of poor SRH with demographic, health and military occupation domains varied depending on the class on the Reserve Force Service. Different strengths of association showed different risk compositions for both populations. This can be used to better understand the health and wellbeing of Veterans of the Reserve Force.

Keywords: Reserve force, Veterans, Canada, Self-rated health, Survey, Risk factors

\footnotetext{
* Correspondence: julian.reyesvelez@canada.ca

Veterans Affairs Canada, Charlottetown, PE C1A 1N2, Canada
}

(c) The Author(s). 2020 Open Access This article is licensed under a Creative Commons Attribution 4.0 International License, which permits use, sharing, adaptation, distribution and reproduction in any medium or format, as long as you give appropriate credit to the original author(s) and the source, provide a link to the Creative Commons licence, and indicate if changes were made. The images or other third party material in this article are included in the article's Creative Commons licence, unless indicated otherwise in a credit line to the material. If material is not included in the article's Creative Commons licence and your intended use is not permitted by statutory regulation or exceeds the permitted use, you will need to obtain permission directly from the copyright holder. To view a copy of this licence, visit http://creativecommons.org/licenses/by/4.0/. The Creative Commons Public Domain Dedication waiver (http://creativecommons.org/publicdomain/zero/1.0/) applies to the data made available in this article, unless otherwise stated in a credit line to the data. 


\section{Background}

The assessment of the general health status and quality of life has been considered a one of the elements of the well-being of the individuals in a population. Self-rated health $(\mathrm{SRH})$ is a commonly used indicator in the psychological and clinical fields in population surveys and is a measure where the individuals rate their own health, as a single question with responses such as: "excellent", "very good", "good", "fair" or "poor" [1]. The self-rated health (SRH) contains a continuum of the health/illness concepts, ranging from positive (absence of illness) to negative concept (not bad to neutral state) [2]. The SRH has been considered as the sum of the person's health status and functional outcomes [2] and a good descriptor of the general health and well-being for a particular population and a predictor of morbidity, mortality [3] and health services utilization [4]. This indicator has been associated with psychological health at an individual level [5], and to chronic health conditions and to acute or transitory illnesses on a lesser degree [6, 7]. Moreover, the SRH measured in adults has shown high correlation with complex health indices, showing the validity of this construct [8].

Different studies have assessed the determinants of SRH in a wide variety of population backgrounds, ranging from minorities, populations with disabilities and developing countries $[2,9]$ and amongst active and retired military members [10-13]. Furthermore, military occupation adds a level of complexity in physical and mental health measurements, since personnel with military service are occupationally exposed to hazardous activities, such as heavy machinery, hazardous activities and unpredictable environments [14]. In personnel transitioning from military service to civilian life, the assessment of different dimensions of well-being have been explored, including the SRH assessment [12].

Multiple demographic factors, social support, marital status, income and occupation amongst others, identified as contextual factors, have been reported in military populations by different authors as having an effect over the functional health status $[10,15]$. One study showed, that self-reports of low health status were associated with higher health utilization following a major deployment [10]. In Canada, the Life After Service Studies (LASS) program designed to increase the understanding of the transition from military to civilian life, has described the well-being of Veterans, including health status and other factors, in Canadian Veterans released since 1998 [16]. This study used the second cycle of LASS from 2013, since this cycle expanded data collection to include Veterans of both Regular Force and the Primary Reserve Force, providing the opportunity to explore more health aspects of this component of the Canadian Forces [17]. Furthermore, a characterization of the
Canadian Reserve Force, has been reported describing outcomes such as: income, occupation, communityfamily support, health-disability and mental health [17]. This study showed, that between 65 to $90 \%$ of the Reserve Veterans with different classes of service presented above average quality of life for physical health [17]. There are differences in the Canadian Forces components (Regular and Reserve Force) due to the nature of service (for example, deployment, combat or domestic responsibilities) and enrollment options (full time vs part time), that could influence the perception of health and the distribution of specific factors. These differences could be carried over the transition to the civilian life. For both components the adaptation to civilian life after a military career can be a challenging event that could exacerbate service or non-service related physical and psychological difficulties [18]. However, there is scarce literature exploring the association of various factors with poor SRH, specifically amongst Reserve Force Veterans and further understanding is needed in this Canadian Forces component after transitioning to civilian life. Therefore, the objectives of this study were to assess the SRH of Veterans of the Canadian Reserve Force, and to identify the association with the demographic, military service and health factors.

\section{Methods}

This research used the LASS 2013 computer assisted cross sectional survey developed by the Research Directorate of Veterans Affairs Canada conducted by Statistics Canada in February-March 2013 [16, 17]. This initiative consisted in a population health research program with the aim of improving the health of Veterans in Canada, through the understanding of the ongoing effects of military service [16]. Canadian Veterans were defined as former members of the Canadian Armed Forces from both components (Regular or Reserve) regardless of their length of service, and their status as clients of VAC [16]. This study assessed only Veterans of the Reserve Force.

\section{Data source}

The data collection for this analysis was conducted as part of the Life After Service (LASS) 2013 study, which included those with service in the Canadian Forces since $1998[16,17]$. The survey consisted in a computer assisted telephone survey conducted by Statistics Canada including 193 questions covering different modules about health disability and health determinants. The population frame included those with service in the Canadian military since 1998. The survey reached 4149 Canadian Veterans with a $70 \%$ response rate and with $90 \%$ of agreement to share the information [19]. The methods of this survey have been described previously in technical reports of the Research Directorate [19]. 


\section{Reserve force classification}

The Reserve Force was composed of professional members of the Canadian Armed Forces with voluntary service, not required for deployment and with part-time and non-continuous employment enrollments [17]. The Reserve Force Veterans were classified as Class $\mathrm{C}$ or Class A/B. Class C were deployed domestically or internationally on a period of full-time service in the Reserve Force between 2003 and 2012, also had periods of Class $\mathrm{A}$ and Class B service and no Regular Force service. Class A/B had a combination of periods of both Class B (temporary full-time) service and Class A (part-time) service between 2003 and 2012, with no periods of Class C or Regular Force service.

\section{Questionnaire description}

The questionnaire included: health status, chronic health conditions, disability, labor force status, social support and health care utilization, as well as some militaryspecific questions. Four domains such as demographic characteristics, physical health, mental health, and military service characteristics, were selected for the present analysis and were extracted from the LASS 2013, covering 14 indicators and were included in this analysis. A detailed description of the variables is presented in the Methodology: Life After Service Studies 2013 [19].

\section{Demographic variables}

The demographic domain included categorical variables for age at release from service $(<30,30-39,40-49,50-$ $59,>60$ ), sex (male and female), education level (less than high school, high school and university degree) and marital status (married or common law and single).

\section{Chronic health characteristics}

Physical health included chronic condition diagnosis (yes or no response) to any of the following conditions: asthma, respiratory (asthma or COPD), diabetes, arthritis, back problems, obesity, cancer, hypertension, hearing impairment. Also measured were life style behaviors such as daily smoking and heavy drinking (five or more drinks per occasion, at least once a month).

\section{Outcome variable}

The SRH was selected as the outcome variable (excellent, very good, good, fair or poor responses). The responses were categorized into two: excellent/very good/ good as the reference category (0) and fair/poor as the risk category (1). The choice of this dichotomization was due to the unbalanced frequency of the original responses. The interest in the present analysis is to high light the difference between those who are doing fair or poor against those categorized as doing well.

\section{Mental health}

The mental health domain module from the LASS 2013 survey included the Self-Perceived Mental Health, corresponding to the question: in general would you say your mental health is?, and was composed of the answer categories: Excellent/Very Good/Good and Fair/Poor. Other variables considered in the analysis were depression (diagnosed with major depression, bipolar disorder, mania or dysthymia), post-traumatic stress disorder, and anxiety disorder (diagnosed with phobia, OCD, panic disorder).

\section{Military service characteristics}

The military service characteristics assessed were length of service ( $<2$ years, 2 to 9 years and 10 to 19 years), enrollment year (1950/60s, 1970s, 1980s, 1990s, 2000s and 2010s), last rank (Officers, Senior Non-commissioned Members (NCM) and Junior NCM), environment (air, land and sea), release type (Involuntary, Medical, Voluntary-Retirement/Service Complete) and military occupation at release (MOC) (combat arms, communications, maritime, aviation, administrative /logistics, engineering/technical, medical and Generalized Operational Services (GOS).

\section{Statistical analysis}

A descriptive analysis of the categorical and continuous variables was performed adjusting for the complex stratified design of the survey. Moreover, a bivariate analysis, for each one of the predictors were performed to explore the frequency distribution of the variables and the relationship with SRH status. A statistical significance of $P<0.1$ was used to select the predictors in the bivariate analysis using a weighted logistic approach to be further considered in the multivariate analysis.

The two Reserve classes were considered separately for the analysis due to their very different service characteristics. Veterans of Reserve Class A/B had mostly part time service, whereas Reserve Class $C$ Veterans had full time service at one point of their career and had other similarities with the Regular Force. In addition, one of the design strata for LASS 2013 survey was the Reserve Class (Reserve A/B and C). A weighted logistic regression model was calculated, assessing first for the significance within each domain of variables using a backward elimination process and then testing the significant variables together for both classes, with a statistical significance of $P<0.05$ used to select the variables for the final model.

Wald tests of composite linear hypotheses for independent variables with more than two categories were performed to explore the overall statistical significance for all categories. Moreover, the potential correlation between predictors, interaction and confounding effects were assessed, correlation of the regression coefficients, testing interaction terms and stratified analysis were 
explored. All the statistical analyses were carried out in STATA version 13.

\section{Results}

The total number of Reserve Class C Veterans was 922 and 476 Class A/B Veterans who participated in the LASS 2013 survey and agreed to share their information with Veterans Affairs Canada. The distribution of the variables of interest by each domain can be found in Table 1. Mainly, Reserve Class C Veterans were older and married compared to Reserve Class A/B Veterans. Also Reserve Class C Veterans reported more arthritis and back problems, served for 10 years or more, had administrative occupations, and were discharged for medical reasons compared with the Reserve Class A/B Veterans (Table 1).

The bivariate analysis is shown in Fig. 1 and Fig. 2 (further detail in the supplementary Tables 1 and 2) for both Reserve Force classes. Different degrees of association were observed for the independent variables. Reserve Class $C$ Veterans had the following independent variables that met the selection criteria for the SRH model: demographic (gender, age, education and marital status), physical health (arthritis, back problems, respiratory, diabetes, obesity, cancer, high blood pressure, hearing and smoking) mental health (depression, anxiety and PTSD), military service (enrollment era, rank, environment, release type and MOC). Reserve Class A/B Veterans had a slightly different list of statistically significant variables: demographics (gender, age, education), physical health (arthritis, back problems, diabetes, obesity, high blood pressure, hearing and smoking), mental health (depression, anxiety, PTSD) military service (length of service, enrollment, rank, environment and release type).

Two different multivariate logistic models were assessed for each Reserve class. These results are presented in Tables 2 and 3. Eleven independent variables were included in both models with different magnitudes of association between the exposure and SRH. Reserve Class $\mathrm{C}$ Veterans included marital status, age, arthritis, back problems, obesity, depression, anxiety, PTSD, type of release. On the other hand, Reserve Class A/B Veterans included education, arthritis, diabetes, obesity, daily smoking and anxiety. In both models the variables arthritis, obesity and anxiety were common.

The Reserve C model was assessed with 891 complete observations, and included 9 variables, of which three were common with the Reserve A/B model. Individuals who were single and had 50-59 years had higher odds for poor SRH than the reference category. Moreover, within the chronic conditions domain having selfreported symptoms of arthritis, back problems, and obesity presented higher odds of poor SRH than those who did not report any of these conditions. The mental health domain showed that depression, anxiety and PTSD were also associated with poor SRH. Within military service characteristics, enrollment and release type were also associated with poor SRH (Fig. 1, Supplementary Table 1), showing that Veterans released for medical reasons had the highest odds when compared with those who retired voluntarily.

The Reserve A/B model was assessed with 468 final observations, and included 6 variables in total, of which three were not used in the Reserve $C$ model (Table 2). From the demographic dimension, having completed high school had higher odds of poor SRH. Moreover, from the physical and mental health dimensions having diabetes, obesity, being a daily smoker, and anxiety increased the odds for poor SRH.

\section{Discussion}

Perceived health indicators, such as SRH, have been widely used in epidemiological research and it has been suggested that SRH reflects non-biologically detectable health conditions [20]. Moreover, SRH has been associated with lifestyle, psycho-social, and socio-demographic conditions [21], and a good predictor of future morbidity and mortality [22]. For the specific case of military personnel and veterans, determinants of SRH have been reported [10, 15]. Military occupation adds a level of complexity in the understanding of health, since armed forces operate in challenging environments with multiple "layers" of occupational hazards [14, 23]. Our results showed that SRH in Veterans of the Canadian Reserve Force can be affected at different magnitudes, by specific factors from the four domains of characteristics (demographics; physical health, mental health, and military service). Based on the knowledge of the authors, this is the first report of SRH amongst Veterans of the Canadian Reserve Force.

Veterans of both Reserve classes had different factors across the four domains related with the SRH outcome. Veterans of Reserve Class $\mathrm{C}$ who were single had a greater odds of poor SRH when compared with being married, but widowed or divorced were not statistically significant different from the reference category. This was consistent with findings of a population based study [23]. Poor SRH among these Veterans was significantly associated with older age, similar to other study among serving and ex-serving UK military personnel [11].

Veterans of Reserve Class A/B presented a reduced number of predictors, including demographic and health variables. Interestingly, age was not significant for these Veterans. This finding could be explained by their age distribution, since $56.5 \%$ were below 30 years. The relationship of lower education with poor SRH in these Veterans is consistent with international research that 
Table 1 Univariate weighted analysis of Demographic, physical health, mental health and military service characteristics of Reserve Force Veterans, by class

\begin{tabular}{|c|c|c|c|c|c|c|c|c|}
\hline \multirow[t]{2}{*}{ Domain } & \multirow[t]{2}{*}{ Variable } & \multirow[t]{2}{*}{ Category } & \multicolumn{3}{|c|}{ Reserve Class C } & \multicolumn{3}{|c|}{ Reserve Class A/B } \\
\hline & & & $\bar{n}$ & $\%$ & $\mathrm{Cl}$ & $\bar{n}$ & $\%$ & $\mathrm{Cl}$ \\
\hline \multirow[t]{14}{*}{ Demographics } & \multirow[t]{2}{*}{ Gender of respondent } & Male & 703 & 76.6 & $(73.8-79.3)$ & 387 & 81.5 & $(77.7-84.7)$ \\
\hline & & Female & 219 & 23.4 & $(20.8-26.3)$ & 89 & 18.5 & $(15.3-22.3)$ \\
\hline & \multirow[t]{5}{*}{ Age } & $<30$ & 135 & 17.1 & $(14.6-19.9)$ & 253 & 56.5 & $(52.0-60.9)$ \\
\hline & & $30-39$ & 366 & 40.6 & $(37.4-43.9)$ & 139 & 27.7 & $(23.9-31.9)$ \\
\hline & & $40-49$ & 184 & 18.7 & $(16.4-21.4)$ & 50 & 9.9 & $(7.6-12.9)$ \\
\hline & & $50-59$ & 150 & 15.2 & $(13.1-17.7)$ & 17 & 3.0 & $(1.9-4.9)$ \\
\hline & & $60+$ & 87 & 8.4 & $(6.8-10.2)$ & 17 & 2.8 & $(1.8-4.5)$ \\
\hline & \multirow[t]{4}{*}{ Education } & Less than HS & 28 & 3.1 & $(2.1-4.5)$ & 10 & 1.9 & $(1.0-3.5)$ \\
\hline & & High School Grad & 234 & 25.9 & $(23.2-28.9)$ & 115 & 25.0 & $(21.3-29.2)$ \\
\hline & & Post Sec $<$ Bach & 376 & 40.9 & $(37.7-44.1)$ & 182 & 38.5 & $(34.1-43.0)$ \\
\hline & & Post Sec $>=$ Bach & 283 & 30.1 & $(27.2-33.2)$ & 168 & 34.6 & $(30.5-39.1)$ \\
\hline & \multirow[t]{3}{*}{ Marital Status } & Married/Common-Law & 673 & 71.8 & $(68.7-74.7)$ & 272 & 56.3 & $(51.8-60.8)$ \\
\hline & & Sep/Wid/Div & 60 & 6.2 & $(4.8-7.9)$ & 21 & 4.3 & $(2.8-6.5)$ \\
\hline & & Single,Never Married & 189 & 22.0 & $(19.4-25.0)$ & 182 & 39.4 & $(35.0-43.9)$ \\
\hline \multirow[t]{20}{*}{ Physical Health } & \multirow[t]{2}{*}{ Arthritis } & Yes & 158 & 16.1 & $(13.9-18.6)$ & 31 & 5.9 & $(4.1-8.3)$ \\
\hline & & No & 757 & 83.9 & $(81.4-86.1)$ & 444 & 94.1 & $(91.7-95.9)$ \\
\hline & \multirow[t]{2}{*}{ Back Problems } & Yes & 297 & 31.5 & $(28.6-34.6)$ & 84 & 17.0 & (13.9-20.6) \\
\hline & & No & 623 & 68.5 & $(65.4-71.4)$ & 392 & 83.0 & $(79.4-86.1)$ \\
\hline & \multirow[t]{2}{*}{ Respiratory } & Yes & 68 & 7.3 & $(5.8-9.2)$ & 26 & 5.6 & $(3.8-8.1)$ \\
\hline & & No & 851 & 92.7 & $(90.9-94.3)$ & 449 & 94.4 & $(91.9-96.2)$ \\
\hline & \multirow[t]{2}{*}{ Diabetes } & Yes & 50 & 4.9 & $(3.7-6.4)$ & 8 & 1.3 & $(0.6-2.6)$ \\
\hline & & No & 870 & 95.1 & $(93.6-96.3)$ & 468 & 98.7 & $(97.4-99.4)$ \\
\hline & \multirow[t]{2}{*}{ Obese } & Yes & 219 & 23.5 & $(20.8-26.4)$ & 86 & 17.8 & $(14.6-21.6)$ \\
\hline & & No & 689 & 76.5 & $(73.6-79.2)$ & 385 & 82.2 & $(78.4-85.4)$ \\
\hline & \multirow[t]{2}{*}{ Cancer } & Yes & 10 & 1.0 & $(0.5-1.9)$ & 4 & 0.8 & $(0.3-2.2)$ \\
\hline & & No & 910 & 99.0 & $(98.1-99.5)$ & 471 & 99.2 & $(97.7-99.7)$ \\
\hline & \multirow[t]{2}{*}{ High Blood Pressure } & Yes & 121 & 12.3 & $(10.4-14.6)$ & 33 & 6.1 & $(4.4-8.6)$ \\
\hline & & No & 796 & 87.7 & $(85.5-89.6)$ & 440 & 93.9 & (91.4-95.6) \\
\hline & \multirow[t]{2}{*}{ Hearing } & Yes & 45 & 4.7 & $(3.5-6.3)$ & 7 & 1.3 & $(0.6-2.8)$ \\
\hline & & No & 847 & 95.3 & $(93.7-96.5)$ & 464 & 98.7 & $(97.2-99.4)$ \\
\hline & \multirow[t]{2}{*}{ Smoker } & Daily Smoker & 120 & 13.4 & $(11.3-15.9)$ & 49 & 10.3 & $(7.8-13.4)$ \\
\hline & & Not Daily Smoker & 802 & 86.6 & $(84.1-88.7)$ & 427 & 89.7 & $(86.6-92.2)$ \\
\hline & \multirow[t]{2}{*}{ Heavy Drinking } & Yes & 244 & 27.8 & $(24.9-30.9)$ & 149 & 31.7 & $(27.6-36.1)$ \\
\hline & & No & 671 & 72.2 & $(69.1-75.1)$ & 323 & 68.3 & $(63.9-72.4)$ \\
\hline \multirow[t]{8}{*}{ Mental Health } & \multirow[t]{3}{*}{ Self-Rated Mental Health } & Excellent/NG & 618 & 67.2 & $(64.1-70.2)$ & 348 & 73.7 & $(69.5-77.5)$ \\
\hline & & Good & 200 & 22.0 & $(19.4-24.9)$ & 97 & 19.9 & $(16.6-23.8)$ \\
\hline & & Fair/Poor & 103 & 10.8 & $(8.9-12.9)$ & 31 & 6.4 & $(4.5-9.0)$ \\
\hline & Depression & Yes & 114 & 12.1 & $(10.2-14.4)$ & 29 & 5.8 & $(4.0-8.3)$ \\
\hline & & No & 807 & 87.9 & $(85.6-89.9)$ & 446 & 94.2 & $(91.7-96.0)$ \\
\hline & Anxiety & Yes & 76 & 8.1 & $(6.5-10.0)$ & 26 & 5.5 & $(3.7-7.9)$ \\
\hline & & No & 843 & 91.9 & $(90.0-93.5)$ & 449 & 94.5 & $(92.1-96.3)$ \\
\hline & PTSD & Yes & 71 & 7.5 & $(5.9-9.3)$ & 9 & 1.8 & $(0.9-3.4)$ \\
\hline
\end{tabular}


Table 1 Univariate weighted analysis of Demographic, physical health, mental health and military service characteristics of Reserve Force Veterans, by class (Continued)

\begin{tabular}{|c|c|c|c|c|c|c|c|c|}
\hline \multirow[t]{2}{*}{ Domain } & \multirow[t]{2}{*}{ Variable } & \multirow[t]{2}{*}{ Category } & \multicolumn{3}{|c|}{ Reserve Class C } & \multicolumn{3}{|c|}{ Reserve Class A/B } \\
\hline & & & $\mathrm{n}$ & $\%$ & $\mathrm{Cl}$ & $\mathrm{n}$ & $\%$ & $\mathrm{Cl}$ \\
\hline & & No & 842 & 92.5 & $(90.7-94.1)$ & 464 & 98.2 & $(96.6-99.1)$ \\
\hline \multirow[t]{24}{*}{ Military Characteristics } & Length of Service & $<2$ years & 7 & 0.9 & $(0.4-1.9)$ & 95 & 20.6 & $(17.1-24.5)$ \\
\hline & & 2 to 9 years & 338 & 41.1 & $(37.9-44.4)$ & 306 & 66.0 & $(61.6-70.1)$ \\
\hline & & 10 to 19 years & 352 & 36.4 & $(33.3-39.5)$ & 55 & 10.1 & $(7.8-13.0)$ \\
\hline & & $>=20$ years & 225 & 21.6 & $(19.2-24.3)$ & 20 & 3.3 & $(2.2-5.2)$ \\
\hline & Enrollment & 1950-80s & 249 & 24.2 & $(21.6-27.0)$ & 25 & 4.4 & $(3.0-6.5)$ \\
\hline & & $1990 \mathrm{~s}$ & 444 & 48.0 & $(44.8-51.3)$ & 86 & 16.1 & $(13.2-19.6)$ \\
\hline & & 2000-10s & 229 & 27.8 & $(24.8-30.9)$ & 365 & 79.4 & $(75.7-82.7)$ \\
\hline & Rank & Officers & 169 & 17.2 & $(14.9-19.7)$ & 51 & 10.2 & $(7.8-13.2)$ \\
\hline & & Senior NCM & 204 & 20.4 & $(18.0-23.1)$ & 22 & 4.0 & $(2.6-6.0)$ \\
\hline & & Junior NCM & 549 & 62.4 & $(59.2-65.5)$ & 403 & 85.9 & $(82.5-88.7)$ \\
\hline & Environment & Air & 67 & 6.9 & $(5.4-8.7)$ & 19 & 3.5 & $(2.2-5.5)$ \\
\hline & & Land & 738 & 80.4 & $(77.7-82.9)$ & 394 & 83.3 & $(79.7-86.4)$ \\
\hline & & Sea & 117 & 12.7 & $(10.7-15.1)$ & 63 & 13.2 & $(10.4-16.6)$ \\
\hline & Release Type & Involuntary & 69 & 9.9 & $(7.9-12.3)$ & 62 & 15.7 & $(12.4-19.5)$ \\
\hline & & Medical & 128 & 12.5 & $(10.6-14.7)$ & 17 & 3.2 & $(2.0-5.0)$ \\
\hline & & Vol/Ret/Service Complete & 725 & 77.6 & $(74.7-80.3)$ & 395 & 81.1 & $(77.2-84.7)$ \\
\hline & Military Occupation & Combat arms & 282 & 43.8 & $(40.0-47.7)$ & 226 & 59.1 & $(54.2-63.9)$ \\
\hline & & Communications & 71 & 10.8 & $(8.7-13.5)$ & 26 & 6.4 & $(4.4-9.3)$ \\
\hline & & Maritime & 51 & 8.0 & $(6.1-10.4)$ & 39 & 9.9 & $(7.3-13.3)$ \\
\hline & & Aviation & 11 & 1.5 & $(0.9-2.8)$ & 4 & 0.8 & $(0.3-2.2)$ \\
\hline & & Admin & 187 & 27.0 & $(23.8-30.6)$ & 60 & 14.9 & $(11.7-18.7)$ \\
\hline & & Engineering & 27 & 3.7 & $(2.5-5.3)$ & 9 & 2.3 & $(1.2-4.4)$ \\
\hline & & Medical & 27 & 4.0 & $(2.7-5.8)$ & 23 & 5.5 & $(3.6-8.1)$ \\
\hline & & GOS & 8 & 1.1 & $(0.5-2.2)$ & 5 & 1.1 & $(0.5-2.6)$ \\
\hline \multirow[t]{3}{*}{ Outcome Variable } & $\mathrm{SRH}$ & Excellent/NG & 554 & 61.2 & $(58.0-64.3)$ & 327 & 69.3 & $(65.0-73.4)$ \\
\hline & & Good & 241 & 25.7 & $(23.0-28.7)$ & 114 & 23.7 & $(20.0-27.7)$ \\
\hline & & Fair/Poor & 127 & 13.1 & $(11.1-15.4)$ & 35 & 7.0 & $(5.0-9.6)$ \\
\hline
\end{tabular}

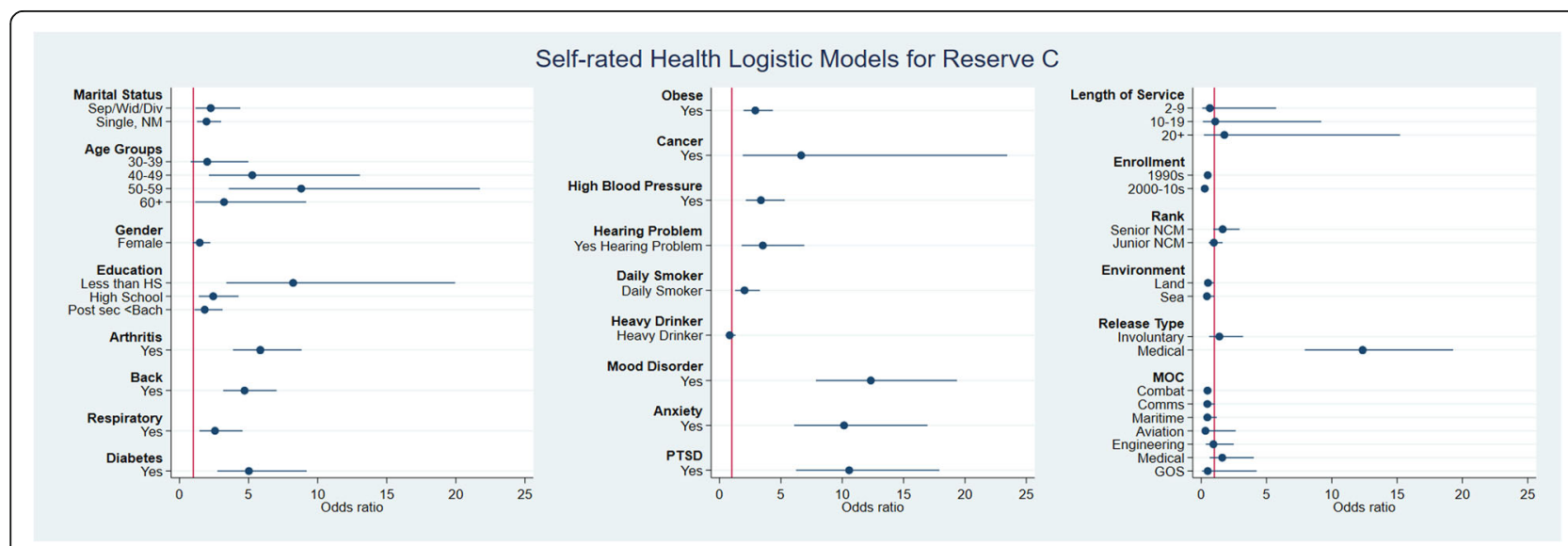

Fig. 1 Bivariate analysis for SRH Demographic, physical health, mental health and military service variables in Reserve Forces Class C 


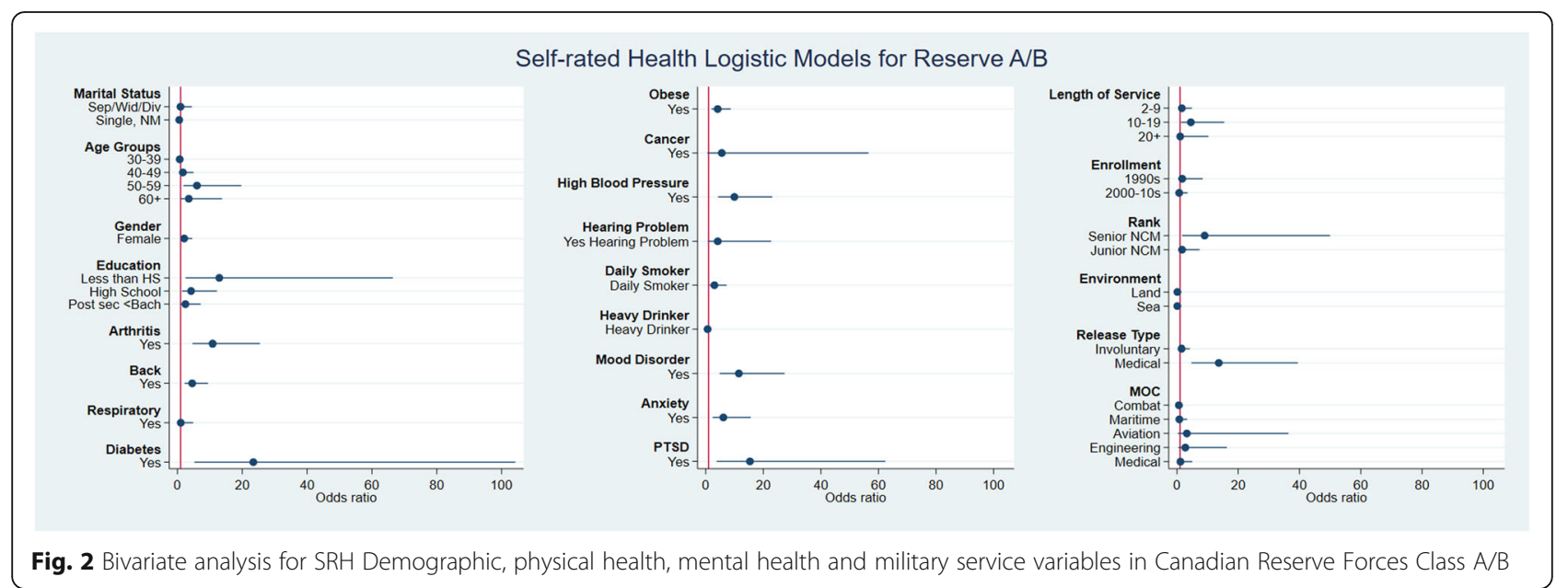

Table 2 Multivariate Logistic model for Self-Rated Health of Veterans of Reserve Class C $(n=891)$

\begin{tabular}{|c|c|c|c|c|c|}
\hline \multirow[t]{2}{*}{ Variables } & \multirow{2}{*}{$\begin{array}{l}\text { Odds } \\
\text { Ratio }\end{array}$} & \multirow{2}{*}{$\begin{array}{l}\text { Std. } \\
\text { Err. }\end{array}$} & \multirow[t]{2}{*}{$P$} & \multicolumn{2}{|c|}{ 95\% Conf Interval } \\
\hline & & & & $\mathrm{IL}$ & UL \\
\hline \multicolumn{6}{|l|}{ Marital Status } \\
\hline Sep/Wid/Div & 1.04 & 0.55 & 0.929 & 0.37 & 2.94 \\
\hline Single, NM & 2.76 & 0.88 & 0.001 & 1.47 & 5.16 \\
\hline \multicolumn{6}{|l|}{ Age } \\
\hline $30-39$ & 1.90 & 1.09 & 0.261 & 0.61 & 5.86 \\
\hline $40-49$ & 2.70 & 1.75 & 0.124 & 0.76 & 9.60 \\
\hline $50-59$ & 4.60 & 3.00 & 0.019 & 1.28 & 17.11 \\
\hline $60+$ & 2.90 & 2.10 & 0.144 & 0.69 & 12.52 \\
\hline \multicolumn{6}{|l|}{ Arthritis } \\
\hline Yes & 2.49 & 0.79 & 0.004 & 1.33 & 4.67 \\
\hline \multicolumn{6}{|l|}{ Back Problems } \\
\hline Yes & 3.02 & 0.82 & 0.000 & 1.76 & 5.16 \\
\hline \multicolumn{6}{|l|}{ Obesity } \\
\hline Yes & 1.96 & 0.54 & 0.016 & 1.13 & 3.38 \\
\hline \multicolumn{6}{|l|}{ Depression } \\
\hline Yes & 2.34 & 0.71 & 0.005 & 1.28 & 4.20 \\
\hline \multicolumn{6}{|l|}{ Anxiety } \\
\hline Yes & 4.11 & 1.50 & 0.000 & 2.00 & 8.42 \\
\hline \multicolumn{6}{|l|}{ PTSD } \\
\hline Yes & 2.09 & 0.81 & 0.055 & 0.98 & 4.47 \\
\hline \multicolumn{6}{|l|}{ Release Type } \\
\hline Involuntary & 1.23 & 0.60 & 0.672 & 0.46 & 3.20 \\
\hline Medical & 4.48 & 1.39 & 0.000 & 2.43 & 8.24 \\
\hline Intercept & 0.00 & 0.01 & 0.000 & 0.00 & 0.02 \\
\hline
\end{tabular}

described an "education gradient" [24]. Since none of the military characteristics were associated with SRH, these Veterans appear to have similar SRH determinants with the general population. Release type may have been difficult to find associated, since most Veterans of Reserve Class A/B released for voluntary reasons, with very few medically discharged.

Reserve Force Veterans of the two classes had different chronic conditions associated with poor SRH. Veterans of Reserve Class $\mathrm{C}$ had SRH associated with several physical conditions (arthritis, back problems and obesity) and mental conditions (depression, anxiety and PTSD). On the other hand, Veterans of Reserve Class A/B had $\mathrm{SRH}$ associated with similar physical conditions of

Table 3 Multivariate logistic model for SRH of Veterans of Reserve Class A/B $(n=468)$

\begin{tabular}{|c|c|c|c|c|c|}
\hline \multirow[t]{2}{*}{ Variables } & \multirow{2}{*}{$\begin{array}{l}\text { Odds } \\
\text { Ratio }\end{array}$} & \multirow{2}{*}{$\begin{array}{l}\text { Std. } \\
\text { Err. }\end{array}$} & \multirow[t]{2}{*}{$P$} & \multicolumn{2}{|c|}{ 95\% Confidence Interval } \\
\hline & & & & $\mathrm{IL}$ & $U L$ \\
\hline \multicolumn{6}{|l|}{ Education } \\
\hline Less than $\mathrm{HS}$ & 2.00 & 1.58 & 0.379 & 0.42 & 9.40 \\
\hline High School & 4.30 & 2.55 & 0.012 & 1.37 & 13.81 \\
\hline Post sec $<$ Bach & 2.05 & 1.19 & 0.215 & 0.65 & 6.44 \\
\hline \multicolumn{6}{|l|}{ Arthritis } \\
\hline Yes & 6.60 & 3.76 & 0.001 & 2.15 & 20.23 \\
\hline \multicolumn{6}{|l|}{ Diabetes } \\
\hline Yes & 11.19 & 8.05 & 0.001 & 2.72 & 46.00 \\
\hline \multicolumn{6}{|l|}{ Obese } \\
\hline Yes & 3.37 & 1.54 & 0.008 & 1.37 & 8.27 \\
\hline \multicolumn{6}{|l|}{ Daily smoking } \\
\hline Yes & 2.98 & 1.56 & 0.039 & 1.05 & 8.38 \\
\hline \multicolumn{6}{|l|}{ Anxiety } \\
\hline Yes & 9.80 & 4.81 & 0.000 & 3.70 & 25.75 \\
\hline Intercept & 0.01 & 0.01 & 0.000 & 0.00 & 0.03 \\
\hline
\end{tabular}


arthritis, diabetes and obesity and interestingly, only anxiety of the mental health conditions was significantly associated with SRH. The different conditions associated with SRH for both reserve classes could be a reflection of the nature of the class of Reserve service and its effects on SRH.

Chronic health conditions, mental health disorders and poor SRH are more frequent in Veterans of Reserve Class $\mathrm{C}$ than Canadians, and these Veterans have similar rates as Regular Force Veterans [18]. On the other hand, Veterans of Reserve Class A/B reported similar rates as the Canadian population [18]. One study in active Canadian regular force members, reported that chronic pain conditions were prevalent and co-occur with mental disorders [13]. The presence of one or more chronic health conditions has been associated with poor SRH in adult populations [25, 26], and specifically diabetes [26]. In our study, each separate chronic condition had an effect on poor $\mathrm{SRH}$, and diabetes had the highest OR for Veterans of Reserve Class $\mathrm{A} / \mathrm{B}$, although the confidence interval of the $\mathrm{OR}$ was wide. The Reserve Class $\mathrm{C}$ had more co-occurring conditions with a higher prevalence of poor $\mathrm{SRH}$, when compared with the Reserve Class A/B. These differences could help for health promotion in both Reserve Classes, stressing the importance of health programs and services during their transition to civilian life.

Amongst the military service characteristics of Veterans of Reserve Class $C$, being released from the service for medical reasons showed the highest odds of poor $\mathrm{SRH}$, when compared to voluntary release (Voluntary/ Retirement/Service Completed). This result was in agreement with an study amongst British Armed Forces, that showed a higher frequency of poor or fair SRH on medically downgraded individuals compared to those not medically downgraded [27], which were more likely to have psychological distress [27]. In contrast, type or release was not associated with SRH among Veterans of Reserve Class A/B.

One of the main strengths of this study is the large sample size, which was representative of Veterans of several Reserve Force classes. Moreover, this study used a large scale survey with objective measures of demographic, military and well-being characteristics using valid instruments. However, the study also has several limitations including the self-reported measures used for health, and the cross sectional nature of the survey, from which causal inference is limited.

\section{Conclusions}

This study showed that specific domains of demography, chronic health conditions and military service can influence with different degrees of association the SRH. Poor SRH amongst Reserve Class $\mathrm{C}$ Veterans was associated with being single, being older and having chronic health conditions such as arthritis, back problems and obesity, or mental health conditions and being medically released. In contrast, fewer associations were found for Veterans with Reserve Class A/B service, showing a different risk composition that included completing at least high school, having a chronic health condition such as arthritis, diabetes and obesity, or anxiety were associated with poor SRH. In general the differences between the Reserve Classes provide insights in to demographic, health and well-being, that will help to inform policies and service delivery, depending on their specific needs derived from the nature of their service. This information can help to understand the relevant factors by Reserve class, that can contribute to improve the general health of Reserve Force Veterans.

\section{Supplementary information}

Supplementary information accompanies this paper at https://doi.org/10. 1186/s12955-020-01516-8.

Additional file 1: Supplementary Material Table 1. Bivariate analysis for SRH of Veterans of Reserve Class C, by demographic, physical health, mental health and military service characteristics, LASS 2013.

Supplementary Material Table 2 Bivariate analysis for SRH of Veterans of Reserve Class A/B, by demographic, physical health, mental health and military service characteristics, LASS 2013.

\section{Abbreviations}

SRH: Self-rated health; LASS: Life after service; OR: Odds ratio; PTSD: Post traumatic stress disorder; NCM: Non-Commissioned Members; MOC: Military occupation; GOS: Generalized Operational Services

\section{Acknowledgements}

The authors would like to acknowledge our participants and to Alexandra Ralling and Madeleine Tweel for their contribution to the manuscript.

\section{Authors' contributions}

$J R$ and JS were involved the design, statistical analysis-interpretation and manuscript writing. AP was involved in the design, data management and manuscript editing, MM and LVT were involved in the design, data interpretation and manuscript editing. The author(s) read and approved the final manuscript.

Funding

Not applicable.

Availability of data and materials

The database used in this report is available in the Research Data Centers operated by Statistics Canada. Further details can be found in the referenced technical report.

\section{Consent for publication}

Not applicable.

\section{Competing interests}

The authors declare that they have no competing interests.

Received: 29 August 2019 Accepted: 29 July 2020

Published online: 24 August 2020

\section{References}

1. Bombak AE. Self-Rated Health and Public Health: A Critical Perspective. Front Public Health [Internet]. 2013;1 Available from: http://journal.frontiersin.org/ article/10.3389/fpubh.2013.00015/abstract, [cited 2019 May 15]. 
2. Manderbacka K. Examining the continuity of self-rated health. Int J Epidemiol. 1998;27(2):208-13.

3. Schnittker J, Bacak V. The Increasing Predictive Validity of Self-Rated Health Noymer A, editor. PLoS One. 2014:9(1):e84933.

4. Xu F, Johnston JM. Self-Rated Health and Health Service Utilization: A Systematic Review. Int J Epidemiol. 2015;44(suppl_1):i180.

5. Rona RJ, Hooper R, French C, Jones M, Wessely S. The meaning of selfperception of health in the UK armed forces. Br J Health Psychol. 2006;11 (4): 703-15.

6. Goldstein MS, Siegel JM, Boyer R. Predicting changes in perceived health status. Am J Public Health. 1984 Jun;74(6):611-4.

7. Pope GC. Medical conditions, health status, and health services utilization. Health Serv Res. 1988;22(6):857-77.

8. Moum T. Self-assessed health among Norwegian adults. Soc Sci Med 1982. 1992;35(7):935-47.

9. Cau BM, Falcão J, Arnaldo C. Determinants of poor self-rated health among adults in urban Mozambique. BMC Public Health [Internet]. 2016;16(1) Available from: https://www.ncbinlm.nih.gov/pmc/articles/PMC4995828/, [cited 2019 May 16].

10. Trump DH. Self-rated health and health care utilization after military deployments. Mil Med. 2006;171(7):662-8.

11. Jenkins SC, Stevelink SA, Fear NT. Factors associated with poor self-reported health within the UK military and comparisons with the general population: a cohort study. JRSM Open. 2017;8(5):205427041769272.

12. Hopman WM, Thompson JM, Sweet J, VanTil L, VanDenKerkhof EG, Sudom $\mathrm{K}$, et al. Multivariate assessment of health-related quality of life in Canadian Armed Forces veterans after transition to civilian life. J Mil Veteran Fam Health. 2015;1 (2):61-70.

13. Vun E, Turner S, Sareen J, Mota N, Afifi TO, El-Gabalawy R. Prevalence of comorbid chronic pain and mental health conditions in Canadian Armed Forces active personnel: analysis of a cross-sectional survey. CMAJ Open. 2018;6(4):E528-36

14. Gauntlett-Gilbert J, Wilson S. Veterans and chronic pain. Br J Pain. 2013 May; 7(2):79-84.

15. Frayne SM, Parker VA, Christiansen CL, Loveland S, Seaver MR, Kazis LE, et al. Health status among 28,000 women veterans. J Gen Intern Med. 2006;21(3): S40-6.

16. VanTil L, MacLean MB, Thompson J, Pedlar D. Life After Service Studies: a program of population health research at Veterans Affairs Canada. In: Shaping the Future: Military and Veteran Health Research [lnternet]. Kingston: Aiken AB, Bélanger SAH:Canadian Defence Academy Press; 2011. p. 317-22. Available from: https://cimvhr.ca/documents/Shaping-the-Future.pdf.

17. VanTil L, MacLean MB, Poirier A, McKinnon K, Keough J, Sudom K, Dursun S, et al. Veterans of the Reserve Force: Life After Service Studies 2013. [Internet]. Research Directorate: Veterans Affairs Canada; 2016. Available from: http://publications.gc.ca/pub?id=9.826344\&sl=0, [cited 2019 May 15].

18. Shields D, Kuhl D, Lutz K, Frender J, Baumann N, Lopresti P. Mental Health and Well-Being of Military Veterans during Military to Civilian Transition: Review and Analysis of the Recent Literature. In: Canadian Institute for Military and Veteran Health Research \& Scientific Authority, Veterans Affairs Canada; 2016. p. 1-174.

19. VanTil L, Perrie S, Poirier P, Sweet J, McKinnon K, MacLean MB, Sudom K, Olson E, Pedlar YJ. Methodology: Life After Service Studies 2013. [Internet]. Research Directorate: Veterans Affairs Canada; 2014. p. 70. Available from: http://publications.gc.ca/pub?id=9.629947\&sl=0.

20. Eriksson I, Undén A-L, Elofsson S. Self-rated health. Comparisons between three different measures. Results from a population study. Int J Epidemiol. 2001;30(2):326-33.

21. Idler EL, Kasl S. Health perceptions and survival: do global evaluations of health status really predict mortality? J Gerontol. 1991;46(2):S55-65.

22. Kaplan GA, Camacho T. Perceived health and mortality: a nine-year followup of the human population laboratory cohort. Am J Epidemiol. 1983; 117(3):292-304.

23. Lindström M. Marital status, social capital, material conditions and self-rated health: a population-based study. Health Policy. 2009;93(2):172-9.

24. Borgonovi F, Pokropek A. Education and self-reported health: evidence from 23 countries on the role of years of schooling, cognitive skills and social capital. PLoS One. 2016;11(2):e0149716.

25. McDaid O, Hanly MJ, Richardson K, Kee F, Kenny RA, Savva GM. The effect of multiple chronic conditions on self-rated health, disability and quality of life among the older populations of Northern Ireland and the Republic of
Ireland: a comparison of two nationally representative cross-sectional surveys. BMJ Open. 2013;3(6):e002571.

26. Mavaddat $\mathrm{N}$, Valderas JM, van der Linde R, Khaw KT, Kinmonth AL. Association of self-rated health with multimorbidity, chronic disease and psychosocial factors in a large middle-aged and older cohort from general practice: a cross-sectional study. BMC Fam Pract. 2014;15(1):185.

27. Rona RJ, Hooper R, Greenberg N, Jones M, Wessely S. Medical downgrading self-perception of health, and psychological symptoms in the British armed forces. Occup Environ Med. 2006;63(4):250-4.

\section{Publisher's Note}

Springer Nature remains neutral with regard to jurisdictional claims in published maps and institutional affiliations.

\section{Ready to submit your research? Choose BMC and benefit from:}

- fast, convenient online submission

- thorough peer review by experienced researchers in your field

- rapid publication on acceptance

- support for research data, including large and complex data types

- gold Open Access which fosters wider collaboration and increased citations

- maximum visibility for your research: over $100 \mathrm{M}$ website views per year

At BMC, research is always in progress.

Learn more biomedcentral.com/submissions 